Check for updates

Cite this: RSC Adv., 2018, 8, 32707

Received 29th June 2018

Accepted 30th August 2018

DOI: $10.1039 / \mathrm{c} 8 \mathrm{ra05561k}$

rsc.li/rsc-advances

\section{A kinetic model for in situ coking denitrification of heavy oil with high nitrogen content based on starch using a structure-oriented lumping method}

\author{
Zhongwen He, ${ }^{a}$ Hui Xu, ${ }^{a}$ Changlu Zhou, ${ }^{a}$ Zhong Xin, (DD *a Jichang Liu ${ }^{b}$ \\ and Benxian Shen ${ }^{b}$
}

In this study, in situ coking denitrification technology was utilized to simplify the entire process by adding an appropriate quantity of denitrification agents to the delayed-coking tower without any further follow-up denitrification process. The effect of starch as the denitrification agent in the in situ coking denitrification process was studied. The distribution of oil products was characterized by GC of simulated distillation. The results indicated that the nitrogen compounds present in heavy oil transformed to coke via in situ coking conversion by reacting with starch. A molecular-level process model for the coking process was developed. Product distribution on the complex reaction network could be described accurately by the model.

\section{Introduction}

The past decade has witnessed the deterioration of crude oil's quality with the increase in demand for the light-fuel products. Delayed coking technology is a very well-rounded process for vacuum residuum and processing in the refining industry, which occupies more than $30 \%$ capacity of the processing ability of world crude oil. ${ }^{1}$ The major product of delayed coking, coker gas oil (CGO), is an important feedstock that is widely used in high-value distillates. Therefore, CGO has attracted attention from oil refineries due to its increasing output and hardness to upgrade. ${ }^{2}$ However, nitrogen compounds present in the CGO need to be removed to produce clean fuels that meet the requirement of environmentally safe processing for environmental safety. ${ }^{3}$

Various techniques have developed for the denitrification of petroleum products including complex extraction, ${ }^{4}$ absorption, ${ }^{5}$ organic or inorganic acid washing, ${ }^{6}$ and hydro-denitrification, ${ }^{7}$ which exhibit significant denitrification effects. In view of the high capital and operational costs of these techniques, in this study, in situ coking denitrification technology was utilized to simplify the entire process by adding an appropriate quantity of denitrification agent to the delayed-coking tower without any further follow-up denitrification process. The proportion of basic nitrogen compounds and total nitrogen compounds in product oil is significantly decreased. More specifically, product distribution and the corresponding molecular compositions

${ }^{a}$ Shanghai Key Laboratory of Multiphase Materials Chemical Engineering, School of Chemical Engineering, East China University of Science and Technology, Shanghai 200237, China.E-mail: xzh@ecust.edu.cn

${ }^{b}$ School of Chemical Engineering, East China University of Science and Technology, Shanghai 200237, China were investigated in order to improve the quality of product oil. Moreover, rational optimization of the equipment and operating conditions were performed with the guidance of reaction kinetic models.

Lumping methods are commonly used to build a kinetic model according to the database. ${ }^{8-10}$ In 1992, Quann and Jaffe proposed the concept of structure-oriented lumping (SOL), which can describe the composition, reaction, and properties of a complex hydrocarbon mixture. ${ }^{11,12} \mathrm{~A}$ composition matrix was established to describe the structures and contents of the molecules, and reaction rules could be used to comply the reaction behaviour of the complex reaction based on this method. Additionally, the SOL method has been extended continually, which makes it suitable to build a kinetic model for complex systems. ${ }^{13-15}$

In this paper, the process conditions of in situ coking denitrification were optimized to achieve the best performance. A molecular level process model for in situ coking denitrification technology was developed to rationally control the product distribution by the SOL reaction kinetic model. Product distribution on the complex reaction network could be described accurately by the model, which is beneficial to reveal the effects of the denitrification agent on the coking process.

\section{Experimental}

\subsection{Materials}

The chemicals used were heavy oil with total nitrogen content of $\sim 5700 \mathrm{ppm}$ and basic nitrogen content of $\sim 1900 \mathrm{ppm}$ (China National Offshore Oil Corporation, China), benzene (99\% purity, Shanghai Lingfeng Chemical Corp., China), acetic acid (99\% purity, Shanghai Tianlian Chemical Technology Co., Ltd., China) and others (starch, perchloric acid, and acetic 
anhydride, 99\% purity Sinopharm Chemical Reagent Co. Ltd, China). The purchased chemicals were used as received.

\subsection{In situ coking denitrification}

Starch or its aqueous solution was used as the denitrification agent. In case of solutions, the mixture was heated at $75{ }^{\circ} \mathrm{C}$ for $1 \mathrm{~h}$ until a uniform solution was obtained. The denitrification agent was added into the system by mixing with $100 \mathrm{~g}$ heavy oils in an appropriate ratio. After pre-coking at $180{ }^{\circ} \mathrm{C}$ for a certain number of hours, the coking tank was maintained at a pressure of $0.2 \mathrm{MPa}$ in nitrogen atmosphere. The coking process was operated at $500{ }^{\circ} \mathrm{C}$ for $6 \mathrm{~h}$. After the solid impurities were filtered, the product was obtained as a yellow liquid with a yield of $50 \pm 5 \%$.

\subsection{Characterization}

The basic nitrogen content of heavy oil was measured using a 2KY-4 Basic Nitrogen Tester (Jiangsu Keyuan Electronic Instrument Co., Ltd., China) according to the standard $\mathrm{SH}$ / T0162. The total nitrogen content was analysed using an Antek 9000 nitrogen/sulfur analyser (Antek, USA) based on the standards H/T 0704-2001 and SH/T 0657-2007. The components of the product oil after coking was analysed using a gas chromatograph spectrometer (GC-14C, Shimadzu, Japan). The char composition after the coking process was investigated using an elemental analyser (Vario EL III, Germany).

\section{Results and discussion}

\subsection{Effect of starch content on N-removal efficiency}

The effect of the starch content on the denitrification process is presented in Fig. 1. It is well known that nitrogen compounds, particularly basic nitrogen compounds, are easily absorbed in the acid active centre of the catalyst and decrease the activity of the catalyst in the catalytic cracking process. Thus, the product yield decreases with the increase in adsorption of the poisonous nitrogen compounds. Therefore, the nitrogen content of the

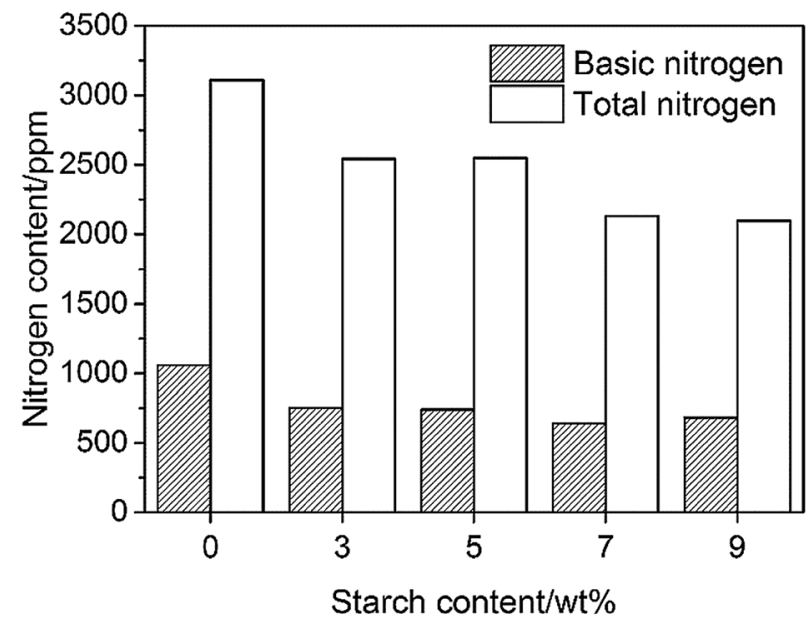

Fig. 1 Effect of the starch content on the nitrogen content of oil. feedstock must be lower than the bearing limit of the catalytic cracking units (basic nitrogen content $\leq 1000 \mathrm{ppm}$, total nitrogen content $\leq 3000 \mathrm{ppm}$ ); the lower the value, the better would be the performance. ${ }^{16}$ As shown in Fig. 1, the total nitrogen content and basic nitrogen content of heavy oil are about 3100 and $1000 \mathrm{ppm}$, respectively, after the coking process, approaching the permissible limit. In the case of the processes containing starch, both the total and basic nitrogen contents decrease significantly. The total N-removal efficiency increases with the increase in starch content before stabilizing at $\sim 32 \%$. A similar tendency is also observed at the basic nitrogen content, which decreases with the increase in the starch content in the range of 3-7 wt\% starch content. A slight increase in the basic nitrogen content is obtained when the starch addition is $9 \mathrm{wt} \%$, indicating the saturation of active sites of the starch. The basic N-removal efficiency of $\sim 40 \%$ is the best performance obtained when starch is used as a denitrification agent directly. In the coking process, the structure of polysaccharide compounds (starch, cellulose) will change significantly by the pyrolysis reactions. ${ }^{17}$ Glucose is the main product at the first step during pyrolysis, which will further decompose to some monomers that undergo dehydration and fragmentation reactions, leading to the formation of chars. The intermediates produced in this process are believed to be the effective species to absorb nitrogen compounds, and will form the chars bundled with nitrogen compounds. Therefore, the nitrogen compounds are removed from the oil. Additionally, Pushkaraj et al. identified some acid species (e.g., $7.52 \mathrm{wt} \%$ formic acid and 0.07 wt $\%$ acetic acid) produced during pyrolysis of glucose,${ }^{17}$ which have close affinity towards basic nitrogen compounds due to the effect of acid-base neutralization.

\subsection{Effect of water on denitrification process}

Table 1 summarizes the effect of water addition on the $\mathrm{N}$ removal efficiency of starch. It is clearly shown that both the total and basic N-removal efficiencies increase apparently by the incorporation of water compared with the system without water under the same operating condition. It was found that $35 \%$ basic N-removal efficiency was obtained for the system involving $5 \mathrm{wt} \%$ starch (in terms of oil) by adding water in oil with $1 / 5$ ratio. In comparison, more than $7 \mathrm{wt} \%$ starch must be added into the system without water in order to obtain similar basic N-removal efficiency. Moreover, the nitrogen content can be further reduced by increasing the water content. The total and basic nitrogen contents decrease respectively to $\sim 1800 \mathrm{ppm}$ and $\sim 660$ ppm by adding water in oil with $2 / 5$ ratio.

Table 1 Effect of water/oil ratio on the N-removal efficiency

\begin{tabular}{|c|c|c|c|}
\hline $\begin{array}{l}\text { Starch } \\
\text { content }^{a}(\%)\end{array}$ & $\begin{array}{l}\text { Water/oil } \\
\text { ratio }\end{array}$ & $\begin{array}{l}\text { Total N-removal } \\
\text { efficiency }^{b}(\%)\end{array}$ & $\begin{array}{l}\text { Basic N-removal } \\
\text { efficiency }^{b}(\%)\end{array}$ \\
\hline 5 & $2 / 5$ & 41.5 & 36.8 \\
\hline 5 & $1 / 5$ & 35.1 & 33.9 \\
\hline
\end{tabular}

${ }^{a}$ wt $\%$ in terms of the heavy oil. ${ }^{b}$ Time of pre-coking: $12 \mathrm{~h}$. 
Accordingly, water incorporation can effectively improve the Nremoval efficiency and also reduce the cost of the materials. This may be attributed to the viscosity reducing effect of water since starch powder will easily stick to the bottom and contact insufficiently with the oil without water. ${ }^{4}$ More specifically, water will promote starch to coke by hydrothermal carbonization during the pre-coking process, which is similar to the process of pyrolysis. ${ }^{18}$ The active species formed in this process can easily bind with the nitrogen components in the heavy oil and produce the chars bundled with nitrogen compounds in the final coking process. In this way, more water is introduced into the system and higher N-removal efficiency will be obtained, which can be concluded from the data listed in Table 1. However, the performance is compromised and high energy consumption will be involved with excess addition of water. Therefore, the appropriate water to oil ratio was $1 / 5$, which was chosen for further study.

\subsection{Effect of pre-coking time on denitrification}

The plots in Fig. 2 show the nitrogen contents measured in the experiments at different pre-coking time. It can be seen that the content of nitrogen compounds decreases significantly after a certain period of pre-coking, which confirms the sufficient hydrothermal carbonization of starch. As we can see from Fig. 2, the N-removal efficiency did not change significantly for precoking times beyond 6 hours. In this regard, 6 hours is undoubtedly the appropriate and economical time period for pre-coking.

\subsection{Characterization of products after coking process}

To better understand the effect of the denitrification agent on the coking process, gas chromatography (GC) and element analysis were performed to characterize the products after coking. The distillation range of oil after coking was measured and listed in Table 2. The distillation temperatures of the control and denitrification samples were nearly the same at the initial distillation until $50 \%$ oil distillation. The difference between the distillation temperatures of the two samples increased from $17{ }^{\circ} \mathrm{C}$ to $64{ }^{\circ} \mathrm{C}$ with the increase in the oil distillation. It seems that the denitrification agent used in this study could not only reduce the content of nitrogen compounds in the oil, but also improve the quality of product oil. The reason

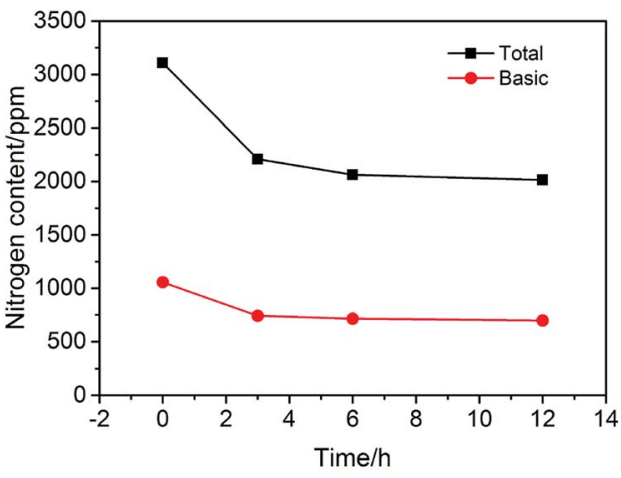

Fig. 2 Effect of precoking time on the nitrogen content of oil.
Table 2 The distillation range of oil after coking ${ }^{a}$

\begin{tabular}{lcc}
\hline Distillation temperature $\left({ }^{\circ} \mathrm{C}\right)$ & Control & Denitrification \\
\hline Initial boiling point & 61.9 & 62.9 \\
$10 \%$ & 72.9 & 75.5 \\
$30 \%$ & 139.0 & 131.9 \\
$50 \%$ & 197.2 & 179.4 \\
$70 \%$ & 264.8 & 228.3 \\
$90 \%$ & 385.9 & 321.8
\end{tabular}

${ }^{a}$ The control sample was obtained by a coking method without adding any denitrification agent. The denitrification sample was obtained by the in situ coking process with the best denitrification agent used in our study (solution was made by mixing of $5 \mathrm{wt} \%$ starch (w.r.t. oil) and water/oil ratio of $1 / 5$ under a $6 \mathrm{~h}$ pre-coking).

may be that some intermediates produced in the hydrothermal carbonization process can catalyse the cracking reaction of heavy oil, thus increasing the content of lighter components, which will be an advantage for the industrial application of the in situ coking denitrification technique.

Table 3 lists the major composition of char. The nitrogen content increases significantly by the incorporation of starch as a denitrification agent, indicating the nitrogen bundle effect of starch, which plays a key role in the in situ coking process.

\subsection{Developing a structure-oriented lumping model (SOL) of in situ coking denitrification}

The lumping method is the most common method for building a kinetic model, which can obtain reliable results on predicting product distribution. In this section, the entire process of building a new kinetic model of in situ coking denitrification by a SOL method was illustrated.

3.5.1 Molecular representation of heavy oil. The specific molecular constitution of heavy oil could not be determined by conventional analytical techniques due to its complicated composition. Hence, it is stimulated in order to establish SOL of in situ coking denitrification and obtain the molecular matrix of heavy oil. Fig. 3 illustrates the schematic of the calculation. First, the residue distillate is cut. The cuts are separated into four components: saturate, aromatics, resins and asphaltenes. The properties of the four components were analysed to obtain the macroscopic property indices, such as the average molecule weight, element components and the average structural parameter. The content of every molecule was preliminarily set in the initial feed matrix. Then, the properties of the feed matrix can be obtained depending on the connection of structure and

Table 3 Composition of major elements of coke ${ }^{a}$

\begin{tabular}{llll}
\hline Sample & $\mathrm{N}(\%)$ & $\mathrm{C}(\%)$ & $\mathrm{H}(\%)$ \\
\hline Control & 0.94 & 92.56 & 3.45 \\
Denitrification & 1.23 & 92.18 & 3.34
\end{tabular}

${ }^{a}$ The control sample was obtained by a coking method without adding any denitrification agent. The denitrification sample was obtained by the in situ coking process with the best denitrification agent in our work (solution made by mix starch of $5 \mathrm{wt} \%$ ratio of oil and water/oil ratio of $1 / 5$ in the solution under a $6 \mathrm{~h}$ precoking). 


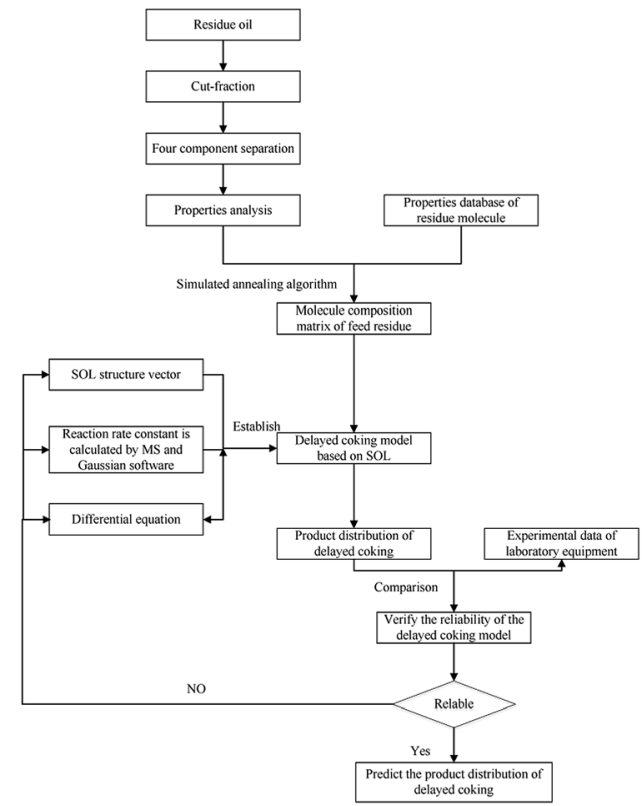

Fig. 3 Flowchart of reaction kinetics model of delayed coking process for heavy oil.

properties. The objective function $\mathrm{F}$ was constructed through the error square sum of the macroscopic properties and the average structural parameter between the calculated and experimental values. The content of each molecule in the feed was adjusted by simulated annealing till the error square sum is smaller than the setting value to obtain the appropriate feed matrix. Combined with the reaction rate constant, which was calculated by Material Studio (BIOVIA USA) and Gaussian software (Gaussian USA) with reaction differential equations, the delayed coking model based on SOL was established. The product distribution, which was calculated by the model, was compared with the product distribution of the experiment. If the error between the calculated data and the experimental data is less than the setting value, the model is reliable, otherwise the parameter of the model should be adjusted till the error is smaller than the setting value. The method to obtain the average structural parameter was fully discussed in our previous study. ${ }^{20}$

(1) Structure increments of heavy oil. A total of 22 structure increments were selected to depict the hydrocarbon and nonhydrocarbon molecule of heavy oil according to the properties of heavy oil and the theory of SOL, which are listed in Table 4.

(2) Selection of seed molecules. According to the characterization results of the molecules in the feed oil using multiple analytical methods, ${ }^{19} 138$ types of seed molecules were designed. The length of carbon chains was determined by the distillation range and molecular weight distribution of the feed. ${ }^{20}$

A total of 138 single-core seed molecules and multi-core seed molecules were selected as the seed molecules of the heavy oil, which are shown partially in Fig. 4. In particular, the homologous series can be obtained by increasing the length of carbon chains of these seed molecules, resulting in 7004 molecules.

Some molecules in heavy oil could be depicted by structure vectors as shown in Table 5 .

The feed composition matrix comprised 7004 rows $\times 23$ columns. The first 7004 rows $\times 22$ columns represented 7004 molecules. The last column in the feed composition matrix was a column vector containing 7004 elements.

(3) Fraction cutting of heavy oil. A supercritical fluid extraction fractionator was used to cut the fraction of heavy oil, as shown in Fig. 5. Eight close cut fractions were obtained, which were investigated by a four component-analytical method to acquire the content of saturated fraction, aromatic fraction, resin and asphaltene as well as the distillation range, elemental

Table 4 Description of 22 structural increments

\begin{tabular}{lllll}
\hline Structural Increment & Structure & Description & Structural increment & Structure \\
\hline Ancription
\end{tabular}




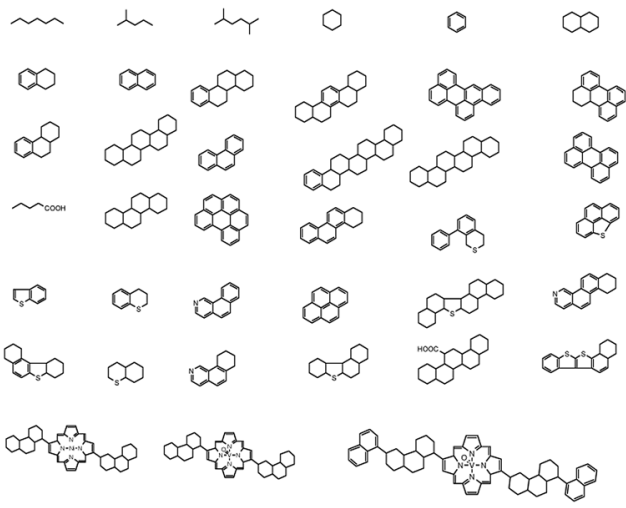

Fig. 4 Single-core seed molecules and multi-core seed molecules.

and structural composition, carbon residue, and molecular weight distribution. The molecular average structural parameters of saturated and aromatic fractions were measured using a gas chromatograph-mass spectrometer (GC-MS, Agilent GC2014, USA). Tables 6 and 7 list the composition of close cut fractions and the MS results of saturated fractions, respectively, when the yield was $60 \%$.

Based on the properties and the average molecular structural parameter of each fraction, the initial contents of the 7004 molecules were set and optimized by a stimulated annealing algorithm to obtain the optimal contents. In the calculation, as the number of molecules in the feed matrix increases, the accuracy of the prediction of the model increases. When the number of molecules exceeds 7004, the improvement in accuracy of the prediction is not evident, but the calculation time increases significantly. Hence, 7004 molecules, which are obtained by increasing the length of carbon chains of these seed molecules, were selected as molecules of the feed. The molecular matrix of each fraction would be established by taking advantage of this information, ${ }^{21}$ and the sum of molecular matrix of the 8 cut fractions was the matrix of the heavy oil. Some virtual molecules and their contents are shown in Table 8, and the values of the properties and structural parameters between experiment and calculation are listed in Table 9. It can be seen that the proposed matrix describes the experimental data satisfactorily. The difference between the experimental value and the calculated value is lower than $9 \%$. Hence, the matrix can be used to develop an in situ coking denitrification model based on a structure-oriented lumping method.

3.5.2 Reaction rules. The oil mainly undergoes two types of reactions during coking: cracking into small molecules and condensing to macromolecules, which include many reactions such as cracking reaction of alkane and dehydrogenation, ringopening reaction of aromatic hydrocarbon, aromatization and cracking reaction of the side chain. There are thousands of reactions comprising the coking reaction. The reactions could be classified into several reaction types such as reactions between glyceraldehyde and pyridine compounds (basic nitrogen compounds) and reactions between hydroxyaldehyde compounds or 5-hydroxymethyl furfural and aniline compounds (basic nitrogen compounds). In order to describe the reactions briefly but accurately, the reaction rules were designed based on the feature of these reaction types. As far as these reactions are concerned, a series of reaction rules were established, having two parts: reactant selection rules and product generation rules, which were used to decide whether a molecule has an appropriate structure for the reaction and the structure vector of the product, respectively. Therefore, 92 reaction rules were established for coking.

During the precoking process, the solution of denitrification agent (starch) was heated up to $180^{\circ} \mathrm{C}$ and the temperature was maintained for 6 hours. The hydrothermal reaction of starch would take place under this condition. The starch would decompose and produce many small molecules with carbonyl, hydroxyl or carboxyl groups, such as dihydroxyacetone, glyceraldehyde, 5-hydroxymethyl furfural and other substances. Fig. 6 displays structures of the products obtained from the hydrothermal reaction of starch.

These molecules could actively react with nitrogen compounds in heavy oil during the coking process. More importantly, these nitrogen compounds would finally discharge as gas or form coke, resulting in the reduction of nitrogen content in the product oil. Some of the reactions between active molecules and nitrogen compounds are shown as follows:

(a) Reaction between glyceraldehyde and pyridine compounds (basic nitrogen compounds):

Table 5 Structure vectors of typical molecules in heavy oil

$\begin{array}{lllllllllllllllllllllllll}\text { A6 } & \text { A4 } & \text { A2 } & \text { N6 } & \text { N5 } & \text { N4 } & \text { N3 } & \text { N2 } & \text { N1 } & \text { R } & \text { br } & \text { me } & \text { IH } & \text { AA } & \text { NS } & \text { NN } & \text { AN } & \text { RO } & \text { KO } & \text { Ni } & \text { V } & \text { cc }\end{array}$

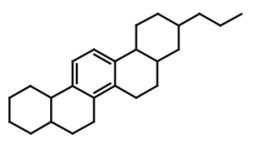

0

0

2

0

02

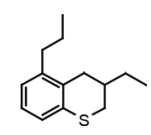

0

0

0

0

0

1

0

0

5

0

0

0

1 


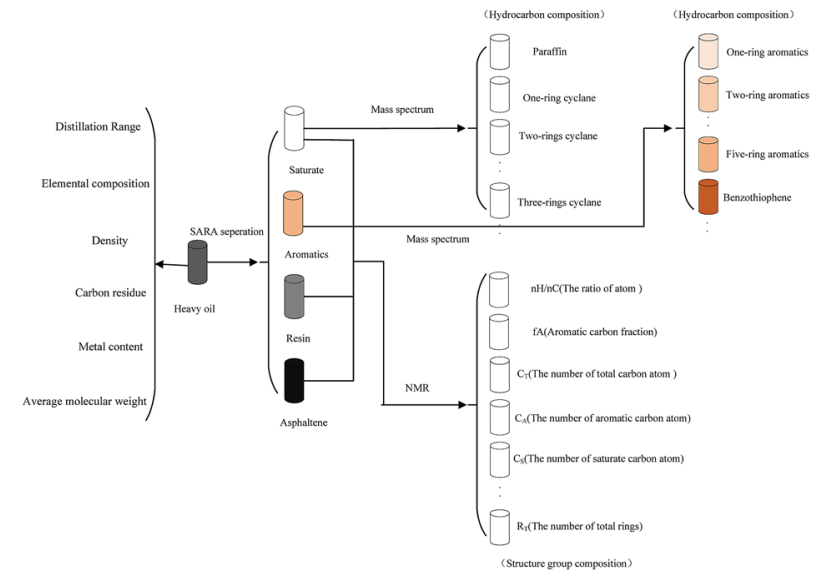

Fig. 5 Fraction cutting of heavy oil.

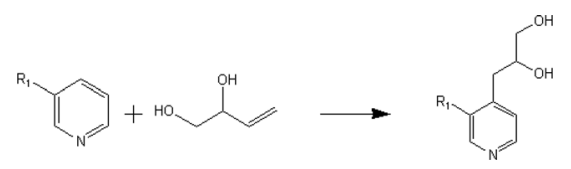

(b) Reaction between hydroxyaldehyde compounds or 5hydroxymethyl furfural and aniline compounds (basic nitrogen compounds):
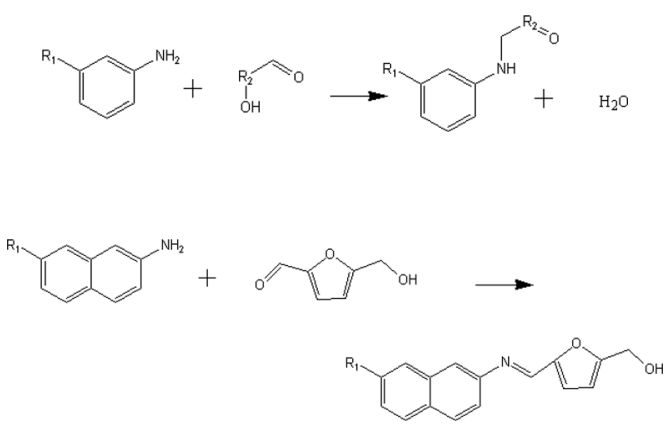

(c) Reaction between hydroxyaldehyde compounds and pyrrole or carbazole compounds (non-basic nitrogen compounds):

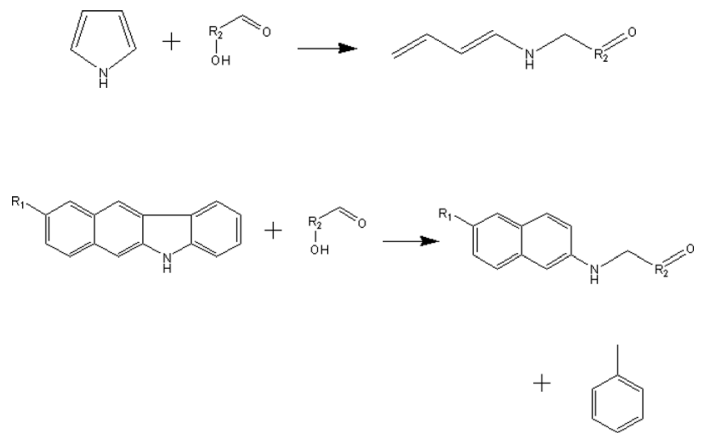

(1) Reaction rules of coking. (a) Cracking reaction of carbon chain:

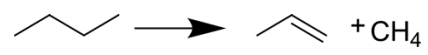

Reactant selection rule: $(\mathrm{A} 6+\mathrm{N} 6+\mathrm{N} 5=0) \wedge(\mathrm{IH}=1) \wedge(\mathrm{RO}+$ $\mathrm{KO}=0) \wedge(R \geq 3)$.

Product 1 generation rule: $R_{1}=1, \mathrm{IH}_{1}=1, \mathrm{br}_{1}=0$.

Product 2 generation rule: $R_{2}=R-R_{1}, \mathrm{IH}_{2}=\mathrm{IH}-1, \mathrm{br}_{2}=(\mathrm{br}$ $\geq 1) \times(R \geq 4)$.

(b) Cracking reaction of side chain:

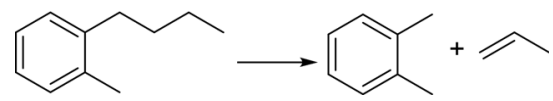

Reactant selection rule: $((\mathrm{A} 6>0) \vee(\mathrm{N} 6>0)) \vee(\mathrm{N} 5>0) \wedge(R$ $\geq 10+\mathrm{KO}) \wedge(\mathrm{A} 6<10) \wedge(\mathrm{N} 6<10)$.

Product 1 generation rule: $R_{1}=$ round $(4+(R-\mathrm{me}-\mathrm{KO}) \times$ round (1)), $\mathrm{br}_{1}=1$, the rest increment is 0 .

Product 2 generation rule: $R_{2}=R-R_{1}, \mathrm{br}_{2}=1$, the rest increment is invariable.

(c) Dehydrogenation:

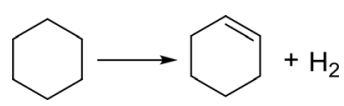

Reactant selection rule: $((\mathrm{A} 6<10) \wedge(\mathrm{N} 6<10)) \wedge((\mathrm{N} 6<10) \vee$ $((\mathrm{N} 4>0) \wedge(\mathrm{NS}+\mathrm{NN}-\mathrm{N} 3-\mathrm{N} 1=0))) \wedge(\mathrm{IH} \geq-1)$.

Product 1 generation rule: $\mathrm{IH}_{1}=1$, the rest increment is 0 .

Table 6 Close cut fraction of heavy oil and their properties

\begin{tabular}{|c|c|c|c|c|c|c|}
\hline Close cut fractions & $\mathrm{C}(\%)$ & $\mathrm{H}(\%)$ & $\mathrm{S}(\%)$ & $\mathrm{N}\left(\mathrm{mg} \mathrm{kg}^{-1}\right)$ & Aryl C (mol\%) & Yield (\%) \\
\hline 1 & 85.48 & 12.11 & 1.80 & 1864 & 10.51 & $20 \%$ \\
\hline 2 & 85.51 & 11.95 & 1.68 & 1863 & 10.80 & $30 \%$ \\
\hline 4 & 85.44 & 11.83 & 1.63 & 2540 & 11.49 & $45 \%$ \\
\hline 5 & 85.52 & 11.99 & 1.76 & 2397 & 11.68 & $50 \%$ \\
\hline 6 & 85.70 & 11.92 & 1.71 & 2365 & 11.84 & $55 \%$ \\
\hline
\end{tabular}

Table 7 Mass spectroscopy results for the saturate

\begin{tabular}{|c|c|c|c|c|c|c|c|c|}
\hline Hydrocarbon composition (\%) & $\mathrm{N}$-alkanes & Isoalkanes & 1-ring & 2-rings & 3-rings & 4-rings & 5-rings & 6-rings \\
\hline Distillate oil & 12.54 & 19.06 & 18.9 & 25.4 & 7.9 & 13.3 & 2 & 0.9 \\
\hline
\end{tabular}


Table 8 Virtual molecules with their contents

$\frac{\text { Virtual molecules }}{\text { Contents (mol\%) }}$

Product 2 generation rule: $\mathrm{IH}_{2}=\mathrm{IH}-1$, the rest increment is invariable.

(d) Synthesis of diene

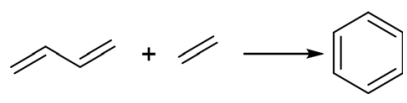

Reactant selection rule: $\left(\mathrm{A} 6_{1}+\mathrm{N} 6_{1}+\mathrm{N} 5_{1}=0\right) \wedge\left(\mathrm{IH}_{1}=-1\right)$. Product 1 generation rule: $\left(\mathrm{A6}_{2}+\mathrm{N}_{2}+\mathrm{N} 5_{2}=0\right) \wedge\left(\mathrm{IH}_{2}=0\right)$.

Product 2 generation rule: N6 $=1, R=R_{1}+R_{2}-6$, IH $=-1$, $\mathrm{br}=0$, me $=\left(\left(R_{1}=5\right)+\left(R_{2}=3\right)\right)$, the rest increment is the sum of the increment of reactant and product.

(2) Reaction rules of the reactions between starch and nitrogen compounds. (a) Reaction between glyceraldehyde and pyridine compounds (basic nitrogen compounds):

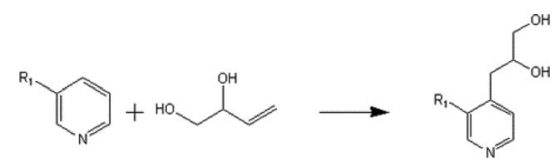

Table 9 Comparison of properties between calculated value and experimental data

\begin{tabular}{|c|c|c|c|}
\hline Properties & $\begin{array}{l}\text { Experimental } \\
\text { value }\end{array}$ & $\begin{array}{l}\text { Calculated } \\
\text { value }\end{array}$ & $\begin{array}{l}\text { Difference } \\
(\%)\end{array}$ \\
\hline Carbon residue, wt\% & 19.65 & 18.33 & -6.72 \\
\hline Molecular weight, $\mathrm{g} \mathrm{mol}{ }^{-1}$ & 623 & 604 & -3.04 \\
\hline $\mathrm{C}, \mathrm{wt} \%$ & 87.50 & 85.36 & -2.45 \\
\hline $\mathrm{H}, \mathrm{wt} \%$ & 11.35 & 11.78 & 3.79 \\
\hline $\mathrm{S}, \mathrm{wt} \%$ & 0.45 & 0.42 & -4.44 \\
\hline $\mathrm{N}, \mathrm{wt} \%$ & 0.55 & 0.58 & 5.45 \\
\hline $\mathrm{Ni}, \mathrm{wt} \%$ & 0.00102 & 0.00108 & 5.88 \\
\hline $\mathrm{V}, \mathrm{wt} \%$ & 0.00120 & 0.00113 & -5.83 \\
\hline \multicolumn{4}{|l|}{ Group composition } \\
\hline Saturate, wt\% & 45.53 & 46.79 & 1.23 \\
\hline Aromatics, wt\% & 38.34 & 36.75 & -4.15 \\
\hline Resin, wt\% & 7.42 & 6.93 & -0.49 \\
\hline Asphaltene, wt\% & 8.56 & 9.24 & 7.94 \\
\hline \multicolumn{4}{|l|}{ Structural composition } \\
\hline $\mathrm{RA}$ & 1.66 & 1.79 & 7.83 \\
\hline RN & 4.72 & 4.31 & -8.69 \\
\hline $\mathrm{fA}, \mathrm{wt} \%$ & 18.74 & 19.23 & 2.61 \\
\hline
\end{tabular}

Fig. 6 Structure of products obtained from the hydrothermal reaction of starch.
Reactant selection rule:

Reactant1: $\mathrm{A6} 6_{1}+\mathrm{N} 6_{1}+\mathrm{N} 5_{1}=0 \wedge\left(\left(R_{1}=3 \wedge \mathrm{RO}_{1}=2\right) \vee\left(R_{1}=\right.\right.$ $\left.\left.4 \wedge \mathrm{RO}_{1}=3\right)\right) \wedge \mathrm{IH}_{1}=0 \wedge \mathrm{KO}_{1}=1$.

Reactant 2: $\mathrm{A6}_{2} \geq 1 \wedge \mathrm{A} 4_{2} \geq 0 \wedge \mathrm{N6}_{2}+\mathrm{N} 5_{2}=0 \wedge R_{2} \geq 0 \wedge \mathrm{IH}_{2}$ $=0 \wedge \mathrm{AN}_{2}=1$.

Product generation rule: $\mathrm{A} 6=\mathrm{A}_{2}, \mathrm{~A} 4=\mathrm{A} 4_{2}, \mathrm{AN}=\mathrm{AN}_{2}, \mathrm{RO}=$ $\mathrm{RO}_{1}, \mathrm{IH}=0$, me $=0$, the rest increment is the sum of the increment of reactant and product.

(b) Reaction between hydroxyaldehyde compounds and aniline compounds (basic nitrogen compounds):

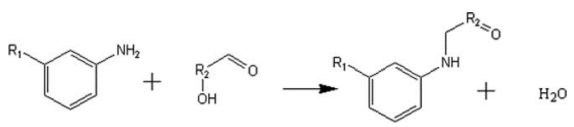

Reactant selection rule:

Reactant 1: $\mathrm{A6}_{1}+\mathrm{N6}_{1}+\mathrm{N} 5_{1}=0 \wedge R_{1} \geq 2 \wedge \mathrm{br}_{1} \geq 0 \wedge \mathrm{IH}_{1}=1 \wedge$ $\mathrm{KO}_{1}=1 \wedge \mathrm{RO}_{1}=1$.

Reactant 2: $\mathrm{A6}_{2}+\mathrm{A} 4_{2} \geq 1 \wedge \mathrm{N6}_{2}+\mathrm{N} 5_{2}=0 \wedge R_{2} \geq 0 \wedge \mathrm{IH}_{2}=$ $0 \wedge \mathrm{RN}_{2} \geq 1$.

Product generation rule: $\mathrm{A} 6=\mathrm{A}_{2}, \mathrm{~A} 4=\mathrm{A} 4_{2}, \mathrm{IH}=0, \mathrm{KO}=0$, $\mathrm{RO}=1$, the rest increment is the sum of the increment of reactant and product.

(c) Reaction between 5-hydroxymethyl furfural and aniline compounds (basic nitrogen compounds):

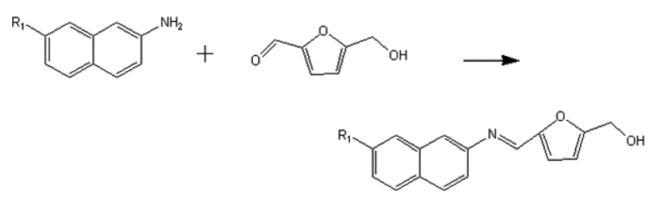

Reactant selection rule:

Reactant1: $\mathrm{A6}_{1}=0 \wedge \mathrm{N} 5_{1}=1 \wedge R_{1}=2 \wedge \mathrm{IH}_{1}=-2 \wedge \mathrm{NO}_{1}=1$ $\wedge \mathrm{KO}_{1}=1 \wedge \mathrm{RO}_{1}=1$

Reactant 2: $\mathrm{A6}_{2}=2 \wedge \mathrm{A}_{2} \geq 0 \wedge \mathrm{AA}_{2}=1 \wedge \mathrm{NN}_{2}=1$.

Product generation rule:

Product 1: $\mathrm{A} 6=1, \mathrm{~A} 4=1, \mathrm{~N} 5=1, \mathrm{AN}=1, \mathrm{IH}=-2, \mathrm{NO}=1$, $\mathrm{RO}=1, R=R_{2}$, the rest increment is the sum of the increment of reactant and product.

Product 2: $\mathrm{A} 6=1, R=1$, the rest increment is 0 .

(d) Reaction between hydroxyaldehyde compounds and carbazole compounds (non-basic nitrogen compounds):
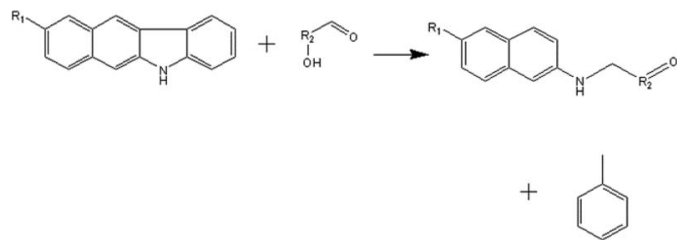

Reactant selection rule:

Reactant1: $\mathrm{A6} 6_{1}+\mathrm{N6}_{1}+\mathrm{N} 5_{1}=0 \wedge R_{1} \geq 2 \wedge \mathrm{RO}_{1}=1 \wedge \mathrm{KO}_{1}=1$. Reactant 2: $\mathrm{A6}_{2}=2 \wedge \mathrm{A} 4_{2} \geq 0 \wedge \mathrm{AA}_{2}=1 \wedge \mathrm{NN}_{2}=1$. Product generation rule:

Product 1: $\mathrm{AA}=0, \mathrm{NN}=0, \mathrm{~A} 6=1, \mathrm{~A} 4=\mathrm{A} 4_{2}, R=R_{2}, \mathrm{NN}=1$, $\mathrm{KO}=1, \mathrm{RO}=0$, the rest increment is the sum of the increment of reactant and product.

Product 2: $\mathrm{A} 6=1, R=1$, the rest increment is 0 . 
(e) Reaction between hydroxyaldehyde compounds and pyrrole or carbazole compounds (non-basic nitrogen compounds):

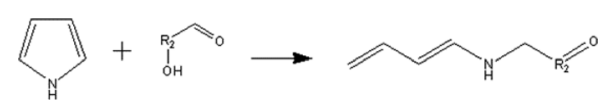

Reactant selection rule:

Reactant 1: $\mathrm{A6}_{1}+\mathrm{N6}_{1}+\mathrm{N} 5_{1}=0 \wedge R_{1} \geq 2 \wedge \mathrm{RO}_{1}=1 \wedge \mathrm{KO}_{1}=1$.

Reactant 2: $\mathrm{A6}_{2}=0 \wedge \mathrm{N}_{2}=1 \wedge \mathrm{NN}_{2}=1 \wedge \mathrm{IH}_{2}=-2$.

Product generation rule: $R=R_{1}+R_{2}+4 ; \mathrm{IH}=-2 ; \mathrm{NN}=1, \mathrm{KO}$ $=1$, the rest increment is the sum of the increment of reactant and product.

Product 2: $\mathrm{A} 6=1, R=1$, the rest increment is 0 .

The sub-amino group in non-basic nitrogen compounds can be converted to the amino group at first, and this new basic nitrogen compound will react with the small molecules decomposed from glucose. Therefore, the intermediate step is neglected in the reaction rules, i.e., the non-basic nitrogen compound reacts directly with small molecules produced from glucose.

3.5.3 Rate constant. There seem to be hundreds of reactions involved in the coking process. It is impossible to obtain the intrinsic rate constant of each reaction. Hence, the method reported by Tian et al., based on the transition state theory, was used to calculate the rate constant of different reactions. ${ }^{22}$ The function of the rate constant calculation is shown in eqn (1):

$$
k(T)=\frac{k_{\mathrm{B}} T}{h} \exp \left(\frac{T \Delta S_{\mathrm{m}}-\Delta E}{R T}\right)
$$

where $k_{\mathrm{B}}$ is the Boltzmann constant, $h$ is the Planck constant, $T$ is the temperature, $R$ is the ideal gas constant, $\Delta S$ is the entropy change before and after reaction, and $\Delta E$ is the reaction energy barrier. Therefore, if $\Delta S$ and $\Delta E$ are known, the reaction rate constant under certain temperatures can be calculated.

In the equation, $\Delta E$ and $\Delta S$ of simple reactions were calculated by Materials Studio as a regression aggregate. The "lsqcurvefit" function and the Matlab optimization toolbox were used, and equations to calculate $\Delta S$ and $\Delta E$ could be obtained. ${ }^{22}$ The common function type is as follows:

$$
y=a_{1} \times x_{1}^{b_{1}}+a_{2} \times x_{2}{ }^{b_{2}}+\ldots+a_{3} \times x_{3}{ }^{b_{3}}+c
$$

As for the numbers of the included elements in the equations, because of the relationship between activity and structure $^{23}$ and because structure vectors were used to describe the molecular structure in the SOL method, the activity could be described by structure vectors.

Starch can react with basic nitrogen compounds and nonbasic nitrogen compounds. The correlation of $\Delta S, \Delta E$ and expressed by structure increments are as follows.

(1) Reaction between glyceraldehyde and pyridine compounds (basic nitrogen compounds):

$$
\begin{gathered}
\Delta E=-0.1948 \times\left(\mathrm{A}_{2}+\mathrm{A} 4_{2}\right)^{0.4013}+0.0519 \times R_{1}{ }^{0.5092}+0.0496 \\
\times R_{2}{ }^{0.1948}+0.5963 \times\left(\mathrm{RO}_{1}+\mathrm{KO}_{1}\right)^{0.3219}+0.8321 \times \mathrm{AN}_{2}{ }^{0.9423} \\
+0.4329 \times \mathrm{NN}_{2}{ }^{0.3141}+0.3145 \times \mathrm{RN}_{2}{ }^{0.2133}
\end{gathered}
$$

$$
\begin{aligned}
\frac{\Delta S}{R}= & 0.0482 \times\left(\mathrm{A}_{2}+\mathrm{A}_{2}\right)^{0.5139}+0.0312 \times R_{1}{ }^{0.3451}-0.0498 \\
& \times R_{2}{ }^{0.9124}+0.0384 \times\left(\mathrm{RO}_{1}+\mathrm{KO}_{1}\right)^{0.4134}+0.0983 \\
& \times \mathrm{AN}_{2}{ }^{0.6183}+0.0456 \times \mathrm{NN}_{2}{ }^{0.4195}+0.0215 \times \mathrm{RN}_{2}{ }^{0.1356}
\end{aligned}
$$

(2) Reaction between hydroxyaldehyde compounds and aniline compounds (basic nitrogen compounds):

$$
\begin{aligned}
\Delta E= & -0.2133 \times\left(\mathrm{A}_{2}+\mathrm{A} 4_{2}\right)^{0.4532}+0.0628 \times R_{1}^{0.5289} \\
& +0.0345 \times R_{2}^{0.1832}+0.5672 \times\left(\mathrm{RO}_{1}+\mathrm{KO}_{1}\right)^{0.3134} \\
& +0.9485 \times \mathrm{AN}_{2}{ }^{0.8953}+0.4132 \times \mathrm{NN}_{2}{ }^{0.3267} \\
& +0.4178 \times \mathrm{RN}_{2}{ }^{0.3614}
\end{aligned}
$$

$$
\begin{aligned}
\frac{\Delta S}{R}= & 0.0517 \times\left(\mathrm{A}_{2}+\mathrm{A} 4_{2}\right)^{0.3769}+0.0486 \times R_{1}^{0.3178}-0.0342 \\
& \times R_{2}^{0.6753}+0.0436 \times\left(\mathrm{RO}_{1}+\mathrm{KO}_{1}\right)^{0.3256}+0.0752 \\
& \times \mathrm{AN}_{2}^{0.5349}+0.0322 \times \mathrm{NN}_{2}^{0.5613}+0.0364 \times \mathrm{RN}_{2}^{0.1592}
\end{aligned}
$$

(3) Reaction between 5-hydroxymethyl furfural and aniline compounds (basic nitrogen compounds):

$$
\begin{aligned}
\Delta E= & -0.2657 \times\left(\mathrm{A}_{2}+\mathrm{A} 4_{2}\right)^{0.3987}+0.0513 \times R_{1}{ }^{0.4728} \\
& +0.0198 \times R_{2}{ }^{0.1936}+0.3893 \times\left(\mathrm{RO}_{1}+\mathrm{KO}_{1}\right)^{0.2896} \\
& +0.8135 \times \mathrm{AN}_{2}{ }^{0.9022}+0.5396 \times \mathrm{NN}_{2}{ }^{0.3654} \\
& +0.3658 \times \mathrm{RN}_{2}{ }^{0.4378}
\end{aligned}
$$

$$
\begin{aligned}
\frac{\Delta S}{R}= & 0.0437 \times\left(\mathrm{A}_{2}+\mathrm{A} 4_{2}\right)^{0.3583}+0.0498 \times R_{1}{ }^{0.2821}-0.0384 \\
& \times R_{2}^{0.5843}+0.0584 \times\left(\mathrm{RO}_{1}+\mathrm{KO}_{1}\right)^{0.3529}+0.0895 \\
& \times \mathrm{AN}_{2}{ }^{0.5432}+0.0376 \times \mathrm{NN}_{2}{ }^{0.5329}+0.0362 \times \mathrm{RN}_{2}{ }^{0.1468}
\end{aligned}
$$

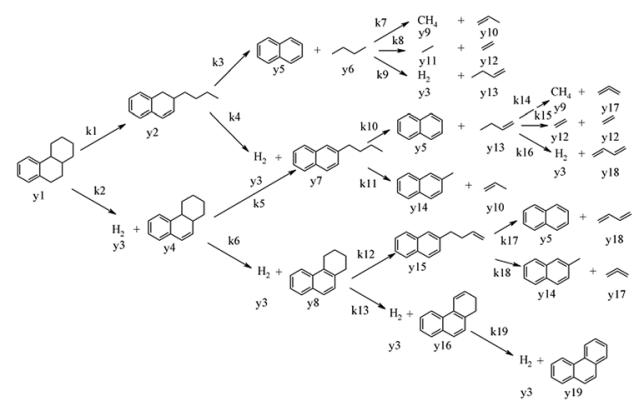

Fig. 7 Reaction network of octahydrophenanthrene during coking. 


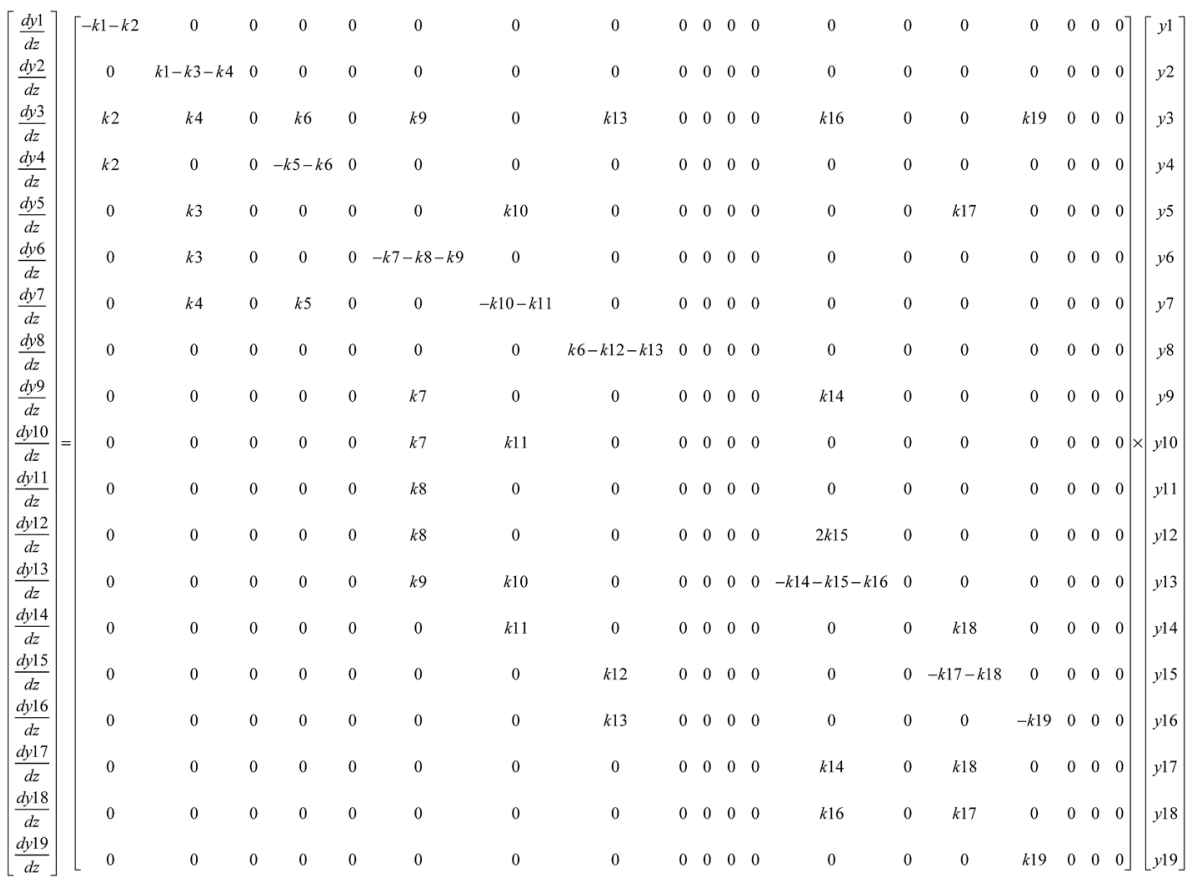

Fig. 8 Kinetic differential equations of octahydrophenanthrene during coking.

(4) Reaction between hydroxyaldehyde compounds and carbazole compounds (non-basic nitrogen compounds):

$$
\begin{aligned}
\Delta E= & -0.3687 \times\left(\mathrm{A}_{2}+\mathrm{A} 4_{2}\right)^{0.5276}+0.0579 \times R_{1}^{0.4319} \\
& +0.0531 \times R_{2}^{0.1832}+0.4729 \times\left(\mathrm{RO}_{1}+\mathrm{KO}_{1}\right)^{0.3087} \\
& +0.9263 \times \mathrm{AN}_{2}^{0.8953}+0.4132 \times \mathrm{NN}_{2}^{0.3267} \\
& +0.4178 \times \mathrm{RN}_{2}^{0.3614}
\end{aligned}
$$

$$
\begin{aligned}
\frac{\Delta S}{R}= & 0.0517 \times\left(\mathrm{A}_{2}+\mathrm{A} 4_{2}\right)^{0.3769}+0.0486 \times R_{1}^{0.3178}-0.0342 \\
& \times R_{2}^{0.6753}+0.0512 \times\left(\mathrm{RO}_{1}+\mathrm{KO}_{1}\right)^{0.3028}+0.0839 \\
& \times \mathrm{AN}_{2}^{0.5129}+0.0287 \times \mathrm{NN}_{2}^{0.4714}+0.0343 \times \mathrm{RN}_{2}^{0.1846}
\end{aligned}
$$

(5) Reaction between hydroxyaldehyde compounds and pyrrole or carbazole compounds (non-basic nitrogen compounds):

$$
\begin{aligned}
\Delta E= & -0.2839 \times\left(\mathrm{A}_{2}+\mathrm{A} 4_{2}\right)^{0.4266}+0.0579 \times R_{1}{ }^{0.4319} \\
& +0.0586 \times R_{2}{ }^{0.1328}+0.4729 \times\left(\mathrm{RO}_{1}+\mathrm{KO}_{1}\right)^{0.3087} \\
& +0.9485 \times \mathrm{AN}_{2}{ }^{0.8953}+0.4132 \times \mathrm{NN}_{2}{ }^{0.3267} \\
& +0.4178 \times \mathrm{RN}_{2}{ }^{0.3614}
\end{aligned}
$$

$$
\begin{aligned}
\frac{\Delta S}{R}= & 0.0517 \times\left(\mathrm{A}_{2}+\mathrm{A}_{2}\right)^{0.3769}+0.0486 \times R_{1}{ }^{0.3178}-0.0342 \\
& \times R_{2}{ }^{0.6753}+0.0512 \times\left(\mathrm{RO}_{1}+\mathrm{KO}_{1}\right)^{0.3028}+0.0945 \\
& \times \mathrm{AN}_{2}{ }^{0.4829}+0.0269 \times \mathrm{NN}_{2}{ }^{0.4532}+0.0324 \times \mathrm{RN}_{2}{ }^{0.1933}
\end{aligned}
$$

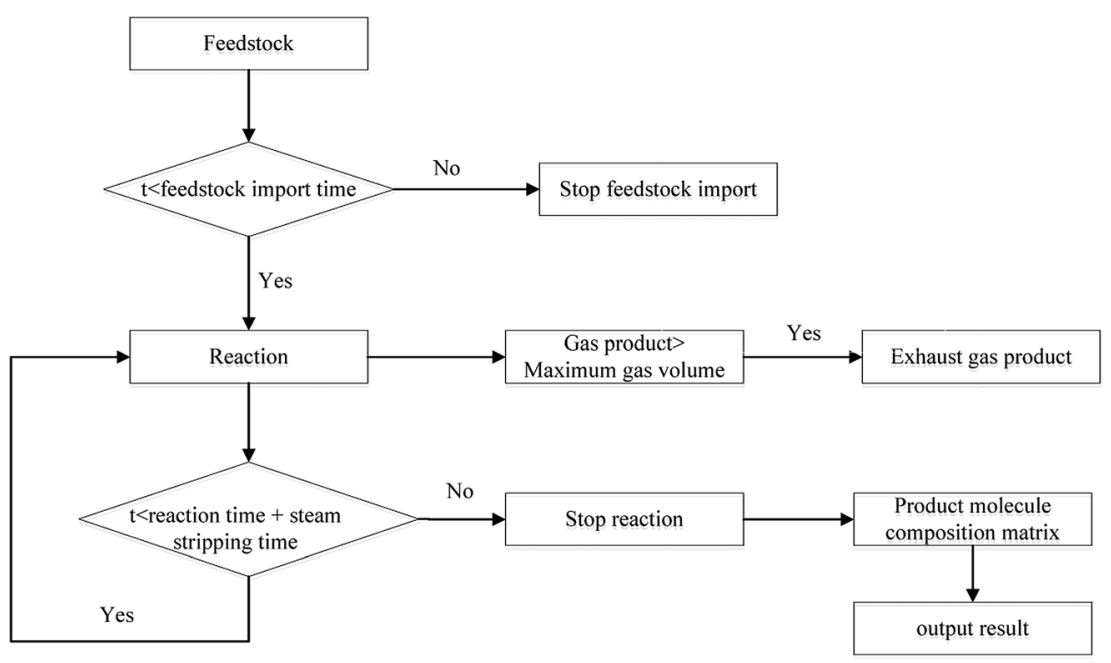

Fig. 9 Calculation diagram for delayed coking reaction process. 
Table 10 Comparison of calculated and experimental distribution of products $^{a}$

\begin{tabular}{|c|c|c|c|c|}
\hline Content/\% & & Gasoline/\% & Diesel/\% & Wax oil/\% \\
\hline \multirow[t]{3}{*}{ Control } & Calculation & 50.4 & 33.5 & 16.1 \\
\hline & Experiment & 50.9 & 32.6 & 16.5 \\
\hline & Error & -0.99 & 2.69 & -2.48 \\
\hline \multirow[t]{3}{*}{3} & Calculation & 54.1 & 31.8 & 14.1 \\
\hline & Experiment & 53.2 & 32.3 & 14.5 \\
\hline & Error & 1.66 & -1.57 & -2.84 \\
\hline \multirow[t]{3}{*}{5} & Calculation & 55.5 & 31.1 & 13.4 \\
\hline & Experiment & 54.3 & 32.0 & 13.7 \\
\hline & Error & 2.16 & -2.89 & -2.23 \\
\hline \multirow[t]{3}{*}{7} & Calculation & 56.4 & 32.3 & 11.3 \\
\hline & Experiment & 57.4 & 31.6 & 11.0 \\
\hline & Error & -1.77 & 2.17 & 2.65 \\
\hline \multirow[t]{3}{*}{9} & Calculation & 59.2 & 30.9 & 9.9 \\
\hline & Experiment & 58.6 & 31.3 & 10.1 \\
\hline & Error & 0.10 & -1.29 & -2.02 \\
\hline \multirow[t]{3}{*}{11} & Calculation & 60.5 & 30.0 & 9.5 \\
\hline & Experiment & 59.5 & 30.8 & 9.7 \\
\hline & Error & 1.65 & -2.67 & -2.11 \\
\hline \multirow[t]{3}{*}{13} & Calculation & 58.9 & 31.9 & 9.2 \\
\hline & Experiment & 59.4 & 31.1 & 9.5 \\
\hline & Error & -0.85 & 2.51 & -2.17 \\
\hline \multirow[t]{3}{*}{15} & Calculation & 58.6 & 31.6 & 9.8 \\
\hline & Experiment & 59.8 & 30.7 & 9.5 \\
\hline & Error & -2.05 & 2.85 & 3.06 \\
\hline
\end{tabular}

${ }^{a}$ The distilled temperatures of gasoline, diesel and wax oil are $<200{ }^{\circ} \mathrm{C}$, $200-320{ }^{\circ} \mathrm{C}$ and $>320{ }^{\circ} \mathrm{C}$, respectively.

3.5.4 Reaction network construction. All coking reactions were considered as first-order reactions. All the reaction networks from reactants to products were produced by reaction rules. Differential equations for describing the kinetic properties of the reaction networks can be formulated conveniently because all of the reactions were first-order reactions. ${ }^{14}$ A simple example is as follows:

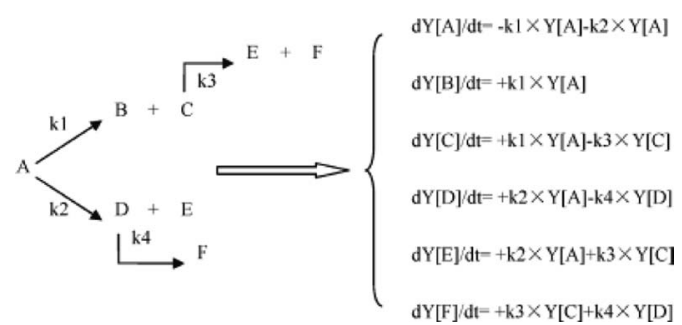

In this model, each reaction rule was formulated as a judgment sentence with Matlab. The matrix of raw materials, which is judged by reaction rules, can determine the reaction path of each molecule. Finally, we can construct an enormous reaction network. Each reaction in the network was described as a differential kinetic equation, and the reactions were operated by solving the equations. Fig. 7 illustrates the reaction network of octahydrophenanthrene during coking, including 19 reactions such as cracking, dehydrogenation, and ring-opening, which involves 19 molecules. The kinetic differential equations of octahydrophenanthrene in delayed coking are listed in Fig. 8.

Although the number of equations will be large with this method, differential equations can be entirely solved with a fourth-to-fifth-order Runge-Kutta algorithm in Matlab because all of the reactions are first-order reactions. The solutions represent the relative content distributions of these 138 seed molecules with time; thus, the product distribution can be predicted.

Table 11 Comparison of calculated and experimental yields at different starch concentrations

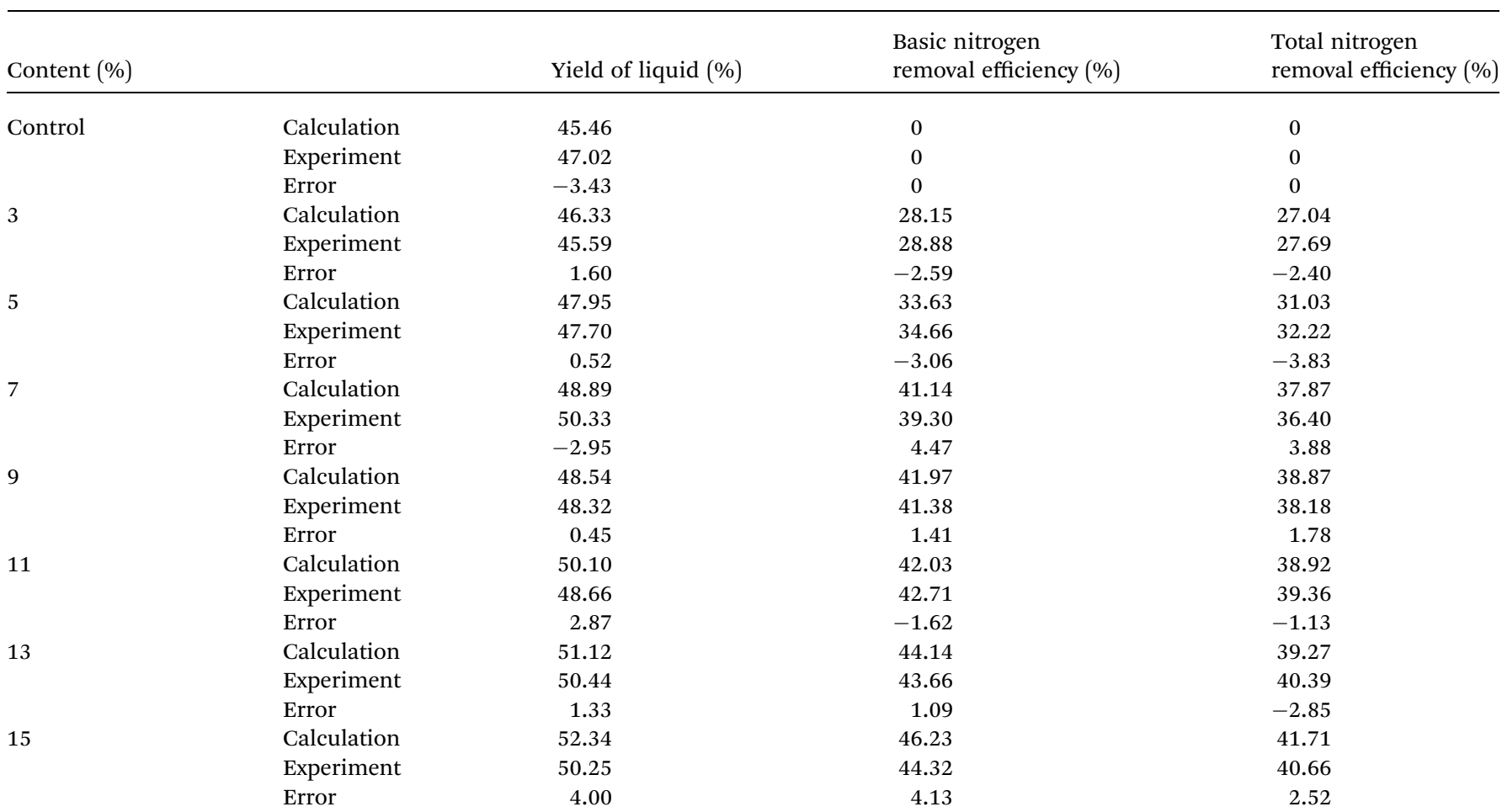


3.5.5 Model-simulated calculation. In this model, the coking process was divided into several sub-periods by time, each of which was $1 \mathrm{~s}$. The calculation process is as follows.

(1) At the beginning of the reaction, the reaction in $1^{\text {st }}$ time period was calculated in order to obtain the distribution of products. The maximum amount of gas in the coking tower was calculated. If the amount of gas produced was greater than the maximum amount of gas, the material was discharged from the discharge port.

(2) After re-feeding, the wax in the tower was discharged and mixed with the raw material based on the cycle. The distribution of products in the next time period was calculated after the mixing process, and the excess gas was discharged.

(3) The above cycle was repeated until the cumulative reaction time was equal to the actual reaction time. Then, the feed was stopped. The distribution of products was calculated at a time interval of $1 \mathrm{~s}$, and the excess gas was discharged.

(4) When the cumulative reaction and the stripping were completed, the molecular matrix of the entire reaction process, that is, the distribution of products of delayed coking, was obtained, and the calculation process is shown in Fig. 9.

The product was divided into various fractions based on the molecular matrix: the molecules below $\mathrm{C} 4$ were classified as coking gas; the molecules with boiling points less than $205{ }^{\circ} \mathrm{C}$ were classified as coking gasoline; the molecules with boiling points between $205^{\circ} \mathrm{C}$ and $365^{\circ} \mathrm{C}$ and atomic number below 24 belong to diesel; the molecules with boiling points higher than $450{ }^{\circ} \mathrm{C}$ and carbon content above $90 \%$ are coke; and others belong to the wax component.

3.5.6 Prediction of products' distribution and effect of in situ coking denitrification by SOL model. Under optimal conditions of the coking reaction at $500{ }^{\circ} \mathrm{C}$, the cycle ratio of 0 , and the ratio of water to heavy oil of $1: 5$, the distribution of the products was calculated by the SOL model with the starch content in the denitrification agent ranging from 0 to $15 \%$. In particular, the results are further compared with experimental data under the same condition, which is shown in Tables 10 and 11.

It can be seen from Tables 10 and 11 that the calculated yields and distribution of the products were in good agreement with the experimental results in the range of $0-15 \%$ starch content, where the relative error was less than $3 \%$ and $9 \%$, respectively. This concludes that the SOL model established in this study can be used to predict the influence of starch content on the distribution of products and denitrification performance.

\section{Conclusion}

In conclusion, starch has been applied to in situ coking denitrification of heavy oil, which can significantly decrease the basic and total nitrogen content. The lowest contents of basic nitrogen and total nitrogen in the product oil are $\sim 40 \%$ and $\sim 30 \%$, respectively. Water incorporation and optimal precoking time was beneficial for the coking process. A molecular level process model for in situ coking denitrification technology was developed to rationally control the product distribution by the SOL reaction kinetic model, which can be used to predict the influence of starch content on the distribution of products and denitrification performance. More importantly, nitrogen compounds in heavy oil are transformed to the chars via in situ directional conversion after the incorporation of starch, which is competitive without other independent denitrification processes (such as extraction tower, absorption and so on) involved besides coking compared with other denitrification techniques reported.

\section{Conflicts of interest}

There are no conflicts to declare.

\section{Acknowledgements}

This work was supported by the Program of Leading Talents (2013), the Fundamental Research Funds for the Central Universities (22A1818025), National Natural Science Foundation of China (21476082).

\section{Notes and references}

1 L. Zekun, W. Gang, S. Quan, X. Chunming and G. Jinsen, Ind. Eng. Chem. Res., 2011, 50, 4123.

2 L. Zekun, W. Gang, L. Yindong, G. Jinsen, X. Chunming, L. Yongmei and W. Xiaoqin, Fuel Process. Technol., 2013, 115, 1.

3 W. Qiang, W. Shihang, T. Xiujuan, Z. Tao, Z. Yasong, C. Keng and X. Chunming, Fuel Process. Technol., 2015, 129, 76.

4 W. Hui, X. Congxia, Y. Shitao and L. Fusheng, Chem. Eng. J., 2014, 237, 286.

5 A. Masoud, M. Xiaoliang and S. Chunshan, Energy Fuels, 2009, 23, 3940.

6 W. Yanzhen, L. Ruili and L. Chenguang, Fuel Process. Technol., 2005, 86, 419.

7 P. E. Boahene, K. Soni, A. K. Dalai and J. Adjaye, Appl. Catal., $B, 2011,101,294$.

8 G. M. Bollas, A. A. Lappas, D. K. latridis and I. A. Vasalos, Catal. Today, 2007, 127, 31.

9 G. Haohua, W. gang, X. Chunming and G. Jinsen, Energy Fuels, 2014, 28, 6554.

10 C. Araujo-Monroy and F. López-Isunza, Ind. Eng. Chem. Res., 2006, 45, 120.

11 R. J. Quann and S. B. Jaffe, Ind. Eng. Chem. Res., 1992, 31, 2483.

12 R. J. Quann and S. B. Jaffe, Chem. Eng. Sci., 1996, 51, 1615.

13 Y. Bolun, Z. Xiaowei, C. Chun, Y. Jun and W. longyan, Ind. Eng. Chem. Res., 2008, 47, 4648.

14 T. Lida, W. Jiming, S. Benxian and L. Jichang, Energy Fuels, 2010, 24, 4380.

15 S. B. Jaffe, H. Freund and W. N. Olmstead, Ind. Eng. Chem. Res., 2005, 44, 9840.

16 B. Hou, Z. Cao, W. Chen and J. Han, Pet. Sci. Technol., 2007, 25, 1013.

17 R. P. Pushkaraj, A. S. Justinus, C. B. Robert and H. S. Brent, J. Anal. Appl. Pyrolysis, 2009, 86, 323.

18 F. Yan, Y. Jun, C. Jie, L. Hui and Z. Xianwei, Fuel, 2016, 180, 591. 
19 E. K. Kim, M. H. No and J. S. Koh, Mass Spectrom. Lett., 2011, $2,41$.

21 R. Zhu, B. Shen, X. Chen and J. Liu, Energy Sources, Part A, 2013, 35, 2010.

20 J. Liu, H. Chen, Z. Pi, Y. Liu, H. Sun and B. Shen, Ind. Eng. 22 L. Tian, B. Shen and J. Liu, Energy Fuels, $2012,26,1715$. Chem. Res., 2017, 56, 3568.
23 L. P. Hammett, J. Am. Chem. Soc., 1937, 59, 96-103. 